\title{
COMO AS CRIANÇAS APRENDEM? UMA REFLEXÃO ACERCA DAS PRÁTICAS PEDAGÓGICAS NUMA PERSPECTIVA INCLUSIVA
}

\author{
Esp. Cecilia Rezende Silva \\ PMU - Prefeitura Municipal de Uberlândia. \\ ceciliarezende@ufu.br ${ }^{14}$ \\ Dra. Myrtes Dias da Cunha \\ Universidade Federal de Uberlândia \\ myrtesufu@gmail.com ${ }^{15}$
}

Resumo: Muito se discute sobre os processos de ensino e aprendizagem. É crescente o percentual de estudantes que apresentam algum tipo de dificuldade. Concomitante é o sentimento de angústia dos profissionais que, por diversos fatores, não conseguem cumprir as metas estabelecidas. Uma questão fundamental precisa ser reavaliada: como as crianças aprendem? Para muitos, basta garantir a permanência dos educandos na escola oferecendo um trabalho de qualidade. Porém, a fórmula do sucesso não é tão simples. São vários interesses e objetivos que se entrecruzam, muitas vezes se chocam, num contexto cada vez mais desestimulante. A escolarização precoce é um dos pontos que merece atenção. As crianças estão sendo submetidas a jornadas exaustivas, principalmente a partir da Lei 12.796/13, que determina que o início da educação básica é aos 4 anos de idade. Um dos objetivos desta é atender a meta da alfabetização até o $2^{\circ}$ ano do ensino fundamental. Dessa forma, os docentes tem priorizado as atividades de leitura e escrita em detrimento das lúdicas, desde os anos iniciais da educação infantil. De acordo com Jacques Rancière (2015) não é necessário sacrificar a infância; as crianças aprendem "apesar" dos professores. É preciso que estes tenham consciência da importância da brincadeira, que reconheçam nesta a gama de conhecimentos que são primordiais para o desenvolvimento das crianças; que valorizem as interações sociais, as leituras de mundo, enfim, que não sobrecarreguem seus alunos transformando 0 ensino em uma atividade desgastante. O aluno Gabriel dos Santos Oliveira, de 5 anos, frequenta o $1^{\circ}$ período da Escola Municipal de Educação Infantil Roosevelt. Diagnosticado com Transtorno do Espectro Autista (TEA), grau severo, é acompanhado no Atendimento Educacional Especializado (AEE) e pelo Centro Especializado em Reabilitação (CER). Na escola, ele não se comunica verbalmente, participa de algumas atividades (sua vontade é respeitada) e permanece parte do tempo fora da sala de

\footnotetext{
${ }^{14}$ Mestranda em Educação pela Faced - Faculdade de Educação da UFU - Universidade Federal de Uberlândia, Linha Saberes e Práticas Educativas. Professora na rede municipal de Uberlândia, com especialização em Educação Especial pela UFU.
}

${ }^{15}$ Professora titular na Faced - Faculdade de Educação da UFU - Universidade Federal de Uberlândia. 
aula. "Apesar" de não realizar todas as tarefas e não se atentar às explicações das professoras, Gabriel é o único aluno da escola que escreve o seu nome completo, o nome de alguns colegas e outras palavras significativas. Em conversa com a mãe soubemos que ele fala e lê conforme seu interesse. A mesma relatou que aos 2 anos ele já sabia todo o alfabeto sem que alguém o ensinasse. Assim como Gabriel, acreditamos que todas as crianças trazem inata a aptidão para aprender! Só precisam ser respeitadas e valorizadas em sua essência!

Palavras-Chave: Educação Infantil. Inclusão. Diferenças humanas.

\title{
INTRODUÇÃO
}

Estudos diversos apontam que, ao longo de muitos anos, a criança frequentava a escola não para se desenvolver de forma saudável e prazerosa; o trabalho escolar tinha o objetivo de preparar esses pequenos cidadãos para 0 mundo do trabalho, assim, as práticas que prevaleciam eram aquelas que iam de encontro aos interesses de mercado. Outro objetivo seria de preparar a criança para futuramente ingressar no ensino obrigatório. Durante a primeira infância a criança pequena precisava ser moldada com os conhecimentos, as habilidades e com os valores culturais dominantes pré-determinados, socialmente sancionados e prontos para serem administrados.

\begin{abstract}
A ideia de infância não existiu sempre da mesma maneira. Ao contrário, ela aparece com a sociedade capitalista, urbano-industrial, na medida em que mudam a inserção e o papel social da criança na comunidade. Se, na sociedade feudal, a criança exercia um papel produtivo direto ("de adulto") assim que ultrapassava o período de alta mortalidade, na sociedade burguesa ela passa a ser alguém que precisa ser cuidada, escolarizada e preparada para uma atuação futura. Este conceito de infância é, pois, determinado historicamente pela modificação nas formas de organização da sociedade (KRAMER, 1982: 18).
\end{abstract}

Com a modernidade pouco mudou. Houve maior interesse na formação da criança. Porém, ao passo que esta foi reconhecida, passou a ter sua liberdade limitada.

A partir do século XIX começaram a se propagar conhecimentos construídos por várias áreas do saber, determinando ações de cuidado, alimentação e higiene infantil. A educação infantil é hoje reconhecida legalmente como primeira etapa da 
educação básica, fase em que os educandos devem desenvolver capacidades e habilidades inerentes a sua faixa etária. No entanto, um crescente debate entre os educadores é quanto a idade inicial do ensino obrigatório. A grande questão colocada é se, ao reduzir essa idade, não se está acelerando a formação de trabalhadores futuros, daí retomada a função da criança nos tempos antigos.

A escolarização precoce pode ocasionar o estresse infantil, que de acordo com Vectore e Horta (2012) um fenômeno que engloba variáveis físicas, psicológicas e ambientais, cujas consequências podem ser danosas, afetando a saúde, as relações interpessoais, dentre outros. Tratar desse assunto no campo das infâncias é bastante complexo. O senso comum considera que problemas de cunho psicológicos são exclusivos dos adultos, economicamente ativos, com pouco tempo para o lazer. Não se concebe estresse aos pequenos que ainda não têm responsabilidades a cumprir. Ou não deveriam ter. As cobranças que se fazem hoje às crianças são bem maiores que se tinha há algumas décadas. Os pequenos são comparados a todo momento, quanto aos mais variados aspectos: aprendizado da leitura, domínio matemático, fluência em língua estrangeira, desempenhos nos esportes, manuseio dos recursos tecnológicos, raciocínio lógico, enfim, as comparações são muitas e geram um mal estar nas crianças que se sentem obrigadas a serem sempre as melhores.

Outro debate que se faz presente é quanto a ação docente. Como estes profissionais estão sendo preparados para lidarem com a infância. De que forma os professores exploram os conhecimentos prévios das crianças que hoje, em geral, estão cercadas de recursos tecnológicos, influência marcante em sua formação pessoal e cultural. Demartini (2009) afirma que há

[...] crianças que têm infância e outras que se vão se constituindo como crianças sem infância. E "sem infância" no sentido de que não passaram por uma experiência que é entendida como experiência de vida que se configuraria essa etapa inicial do processo de socialização (DEMARTINI, 2009: 8-9).

Podemos considerar que "sem infância" seria a falta de experimentação, o espaço mínimo para a criação e as dificuldades de socialização? Gaston Bachelard (1996) afirma que é preciso o tempo certo para que cada ser cresça e produza, um 
prazo concreto e individual. E qual seria o tempo educacional da criança? Como determinar que seja uma quantidade de anos estabelecida, se a subjetividade de cada uma é particular e seu ritmo também? O tempo para a criança da cidade, oriunda de uma família estabilizada social e economicamente é o mesmo tempo da criança que padece de fome? Podemos colocar no mesmo nível e assim generalizar o aluno da escola privada central e o aluno da escola pública de periferia? Como cobrar os mesmos conhecimentos em atividades avaliativas diante de tanta diversidade?

Os Referenciais Curriculares Nacionais para a Educação Infantil (RCNEl'S) estabelecem os conteúdos, denominados eixos de trabalho: movimento, música, artes visuais, linguagem oral e escrita, natureza e sociedade, matemática. Os documentos trazem orientações didáticas propondo um ensino contextualizado e integralizado. Para as crianças de quatro a seis anos, o RCNEI volume 3 propõe as práticas de leitura:

Participação nas situações em que os adultos lêem textos de diferentes gêneros, como contos, poemas, notícias de jornal, informativos, parlendas, trava-línguas etc.

Participação em situações que as crianças leiam, ainda que não o façam de maneira convencional.

Reconhecimento do próprio nome dentro do conjunto de nomes do grupo nas situações em que isso se fizer necessário. Observação e manuseio de materiais impressos, como livros, revistas, histórias em quadrinhos etc., previamente apresentados ao grupo.

Valorização da leitura como fonte de prazer e entretenimento.

(RCNEI, 1998: 140-141)

Em "Participação em situações que as crianças leiam" está registrada a nota de rodapé 37 do documento que esclarece: "Entende-se que a criança é capaz de ler na medida em que a leitura é compreendida como um conjunto de ações que transcendem a simples decodificação de letras e sílabas [...] a partir de indícios fornecidos pelo contexto..." (RCNEI, 1998: 140). Partindo desta proposição, podemos buscar entre os educadores dos anos finais da educação infantil (4 e 5 anos) e do primeiro ano do ensino fundamental (6 anos), por que cada vez mais cedo se exige que a criança esteja lendo e escrevendo plenamente. Pautados em qual princípio reduzem ao mínimo o tempo livre para as brincadeiras em favor de longos horários sentados, enfileirados e calados, copiando exaustivamente 
conteúdos escritos na lousa... Sabe-se que, a partir da Lei 12.796/13, o início da educação básica é aos 4 anos de idade, onde um dos objetivos desta é atender a meta da alfabetização até o final do $2^{\circ}$ ano do ensino fundamental. No entanto, com as rotinas exaustivas de atividades escritas corre-se o risco de surgirem déficits que futuramente poderão até ser confundidos com algum tipo de transtorno. É o que podemos observar em algumas escolas, no Atendimento Educacional Especializado (AEE): crianças com dificuldades de aprendizagens sem nenhum tipo de comprometimento, seja físico ou mental.

Sabemos que o AEE, por ser pedagógico, não depende de laudo médico ${ }^{16}$. Este, para a escola, se caracteriza apenas como instrumento de identificação das dificuldades a serem trabalhadas. O problema é que muitos alunos são encaminhados, já com uma grande defasagem de aprendizado, por carências que não foram supridas, dificuldades que tomaram proporções ao ponto de não poderem ser sanadas em sala de aula no horário regular. Um dos motivos é a má formação docente que, ainda realizando um trabalho tradicional de transmissão do conhecimento, não reconhece as peculiaridades de cada educando e suas variadas formas de aprendizagem.

Almeida e Mahoney (2007) exemplificam o caso de Albert Einstein, um gênio da física, que durante os seus primeiros anos de escolarização apresentou déficit de atenção, dificuldade para se adaptar às normas da escola, chegando a ser desacreditado por seus professores. Chegou a ser suspenso da escola várias vezes porque seu comportamento atrapalhava o bom andamento das aulas. Por sorte ele não foi condenado por um laudo, sua inteligência não foi apagada com drogas tranquilizadoras. Se fosse nos dias de hoje certamente a história teria tomado outra direção.

O RCNEI (1998), volume1, estabelece que a educação especial:

termo cunhado para a educação dirigida aos portadores de deficiência, de condutas típicas e de altas habilidades, é considerada pela Constituição brasileira, como parte inseparável do direito à educação.

\footnotetext{
16 Nota técnica 04/2014. Disponível em < http://portal.mec.gov.br/secretaria-de-educacao-continuadaalfabetizacao-diversidade-e-inclusao/legislacao> 
A posição da UNESCO, considera a educação especial como uma forma enriquecida de educação em geral, que deve contribuir para a integração na sociedade dos portadores de deficiência, de condutas típicas e de altas habilidades. (...) O principal desafio da Escola Inclusiva é desenvolver uma pedagogia centrada na criança, capaz de educar a todas, sem discriminação, respeitando suas diferenças; uma escola que dê conta da diversidade das crianças e ofereça respostas adequadas às suas características e necessidades, solicitando apoio de instituições e especialistas quando isso se fizer necessário. É uma meta a ser perseguida por todos aqueles comprometidos com o fortalecimento de uma sociedade democrática, justa e solidária. (RCNEI, 1998: 36)

No trecho "desenvolver uma pedagogia centrada na criança, capaz de educar a todas, sem discriminação, respeitando suas diferenças" (RCNEI, 1998: 36) fica claro que o olhar não deve ser voltado apenas para quem tem algum tipo de deficiência. Cada ser humano é único, dotado de capacidades e limitações, assim, as práticas pedagógicas devem considerar essa diversidade. De acordo com Mantoan (2015)

As escolas inclusivas propõem um modo de organização do sistema educacional que considera as necessidades de todos os alunos, estruturado em função dessas necessidades. A inclusão implica uma mudança de perspectiva educacional, pois não atinge apenas alunos com deficiência e os que apresentam dificuldades de aprender, mas todos os demais, para que obtenham sucesso na corrente educativa geral. Todos sabemos, porém, que a maioria dos que fracassam na escola não vem do ensino especial, mas possivelmente acabará nele. (MANTOAN, 2015: 28)

É possível desenvolver um trabalho de "prevenção", ou seja, tentar sanar as dificuldades dos educandos antes que estas superem as capacidades e a autoestima dando lugar ao já citado estresse infantil, e consequentemente, o encaminhamento ao AEE. E como isso é possível? A falha está nos cursos de formação? Precisamos refletir quantos a essas questões urgentes que tanto tem afetado o ensino em geral.

\section{POR UMA PRÁTICA PEDAGÓGICA INCLUSIVA}

Muito se discute sobre os processos de ensino e aprendizagem. É crescente o percentual de estudantes que apresentam algum tipo de dificuldade, e assim são 
encaminhados ao AEE. Concomitante é o sentimento de angústia dos profissionais que, por diversos fatores, não conseguem cumprir as metas estabelecidas. Uma questão fundamental precisa ser reavaliada: como as crianças aprendem? Sabemos que os interesses dos alunos e os objetivos dos professores nem sempre coincidem, muitas vezes se chocam, num contexto cada vez mais desestimulante. É comum encontrarmos docentes que anseiam pelo cumprimento dos programas enquanto os discentes querem simplesmente brincar. Para Medrano (2004):

As crianças brincam. Brincam apesar dos adultos, apesar do interesse dos adultos por facilitá-lo ou inibi-lo. O brincar é um trabalho, a partir do qual a criança vai construindo a sua subjetividade e estabelecendo laço social. É, ainda, a fala da criança. Corpo, linguagem e brincar são uma tríade sobre a qual se sustenta o esqueleto desiderativo-libidinal que abre as portas para a constituição da subjetividade. (MEDRANO, 2004: 31).

É preciso que os professores tenham consciência da importância da brincadeira, que reconheçam nesta ação a gama de conhecimentos que são primordiais para o desenvolvimento das crianças; que valorizem as interações sociais, as leituras de mundo, enfim, que não sobrecarreguem seus alunos transformando o ensino em uma atividade desgastante.

O aluno Gabriel dos Santos Oliveira, de 5 anos, frequenta o $1^{\circ}$ período da Escola Municipal de Educação Infantil Roosevelt. Diagnosticado com Transtorno do Espectro Autista (TEA), grau severo, é atendido no AEE e no Centro Especializado em Reabilitação (CER) da rede municipal de saúde. Na escola, ele não se comunica verbalmente, participa de algumas atividades (sua vontade é respeitada) e permanece parte do tempo fora da sala de aula. "Apesar" de não realizar todas as tarefas e não se atentar às explicações das professoras, Gabriel é o único aluno da escola que escreve o seu nome completo, o nome de alguns colegas e outras palavras para ele significativas. Em conversa com a mãe soubemos que ele fala e lê conforme seu interesse. A mesma relatou que aos 2 anos ele já sabia todo o alfabeto sem que alguém o tivesse ensinado. Freitas (2005) em sua tese de doutorado afirma que pessoas com comprometimento sensorial tem um modo diferente de perceberem e se relacionarem com o mundo.

As imagens que seguem são o exemplo de uma atividade realizada de forma "diferente" por Gabriel. Após a apreciação da música "Aquarela" (1983) do artista 
Toquinho, foi solicitado que as crianças ilustrassem alguns trechos no caderno. Aparentemente, Gabriel não estava ouvindo as explicações, estava de costas, agitado, se balançando. Se recusou a fazer a atividade. Depois apontou para o pincel; na escola ele não conversa, apenas aponta ou demonstra gestualmente o que quer. $\mathrm{O}$ aluno só escreve ou desenha em papéis grandes, no chão ou na lousa. Então Gabriel começou a fazer a luva, usando a mão como molde, conforme orientação dada anteriormente ao grupo. Ao ser solicitado que fizesse o segundo desenho, ele teve a criatividade de transformar sua luva em gaivota, conforme visualizamos nas fotografias:

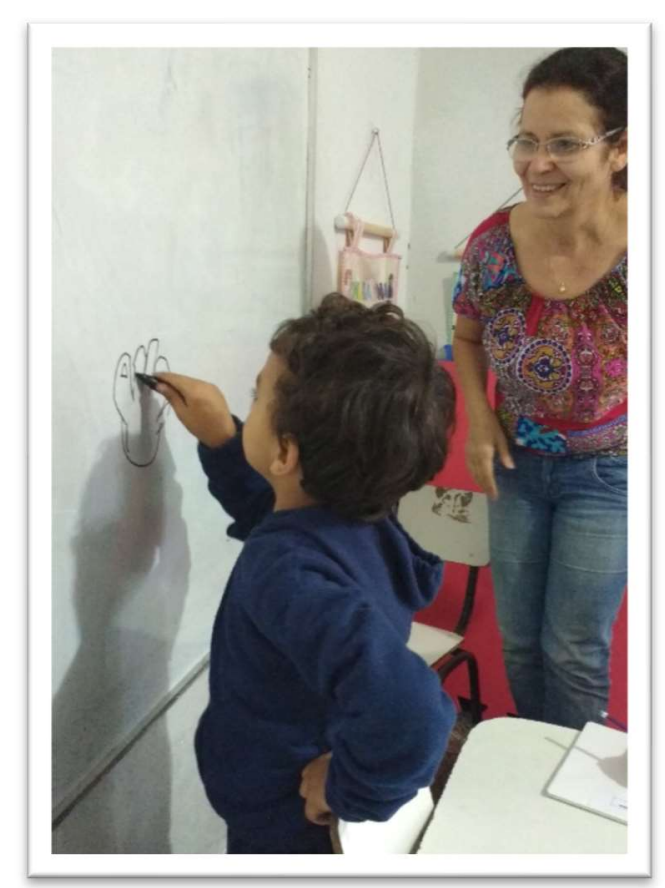

Figura 1: “... corro o lápis em torno da mão e Ihe dou uma luva..."

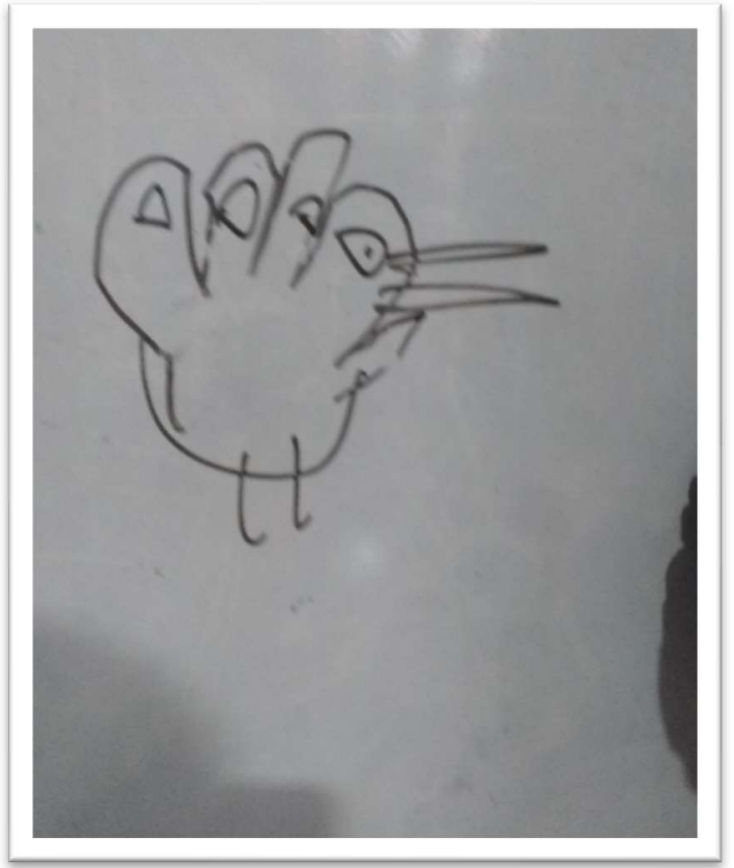

$\mathrm{Na}$ sequência, o aluno escreveu seu nome completo e o nome de alguns colegas, mas o menino não gosta de ser fotografado, se agita e desfaz o foco.

Diante do exemplo de Gabriel, analisemos a afirmação: "Não há homem sobre a Terra que não tenha aprendido alguma coisa por si mesmo e sem mestre explicador" (RANCIĖRE, 2015: 35). Ninguém ensinou o menino a desenhar ou a escrever o nome dos colegas. Rancière (2015) afirma que a inteligência é atenção e 
busca; "é a falta de vontade que faz errar a inteligência. O pecado original do espírito não é a precipitação - é a distração, a ausência" (RANCIÈRE, 2015: 84). O autor afirma que todos os homens têm em comum a capacidade de aprender.

Não há ignorante que não saiba uma infinidade de coisas, e é sobre este saber, sobre esta capacidade em ato que todo ensino deve se fundar. Instruir pode, portanto, significar duas coisas absolutamente opostas: confirmar uma incapacidade pelo próprio ato que pretende reduzi-la ou, inversamente, forçar uma capacidade que se ignora ou se denega a se reconhecer e a desenvolver todas as consequências desse reconhecimento. $O$ primeiro ato se chama embrutecimento e o segundo, emancipação. (RANCIÈRE, 2015: 11-12).

Existem hoje inúmeras pesquisas acerca do TEA. O tema é relativamente novo. Estudos apontam causas, sintomas, alternativas educacionais, terapias, entre outros. No entanto, o que muitas pessoas se esquecem é que cada autista é um ser humano, portanto, dotado de características peculiares; o que existem são alguns sintomas que podem ou não ser semelhantes. Independente de se ter um diagnóstico, não existe quem não tenha algum tipo de limitação ou dificuldade, seja motora, psicológica, cognitiva, etc.

Medrano (2004) aponta

a necessidade de articular, nas micropolíticas institucionais, o debate entre os diferentes atores, na procura de uma pluralidade discursiva que possa conviver com a diferença e que aceite os diferimentos próprios a cada um dos saberes em jogo". (MEDRANO, 2004: 147).

Diante deste cenário de pluralidades, qual é o papel docente para a implantação efetiva da inclusão? De acordo com Matoan (2015) a função docente deve ser ressignificada. Vigotsky (2010) faz um apanhado destacando que toda teoria da educação apresenta suas exigências ao mestre:

Para a pedagogia de Rousseau, o mestre é apenas o vigia e protetor da criança contra a perversão e as más influências. Para Tolstói, o mestre deve ser forçosamente um homem virtuoso, capaz de contagiar a criança com sua experiência pessoal. Para a pedagogia ascética o educador é quem sabe pôr em prática os ensinamentos: "quebra a vontade de tua criança para que ela não se destrua". (...) Para Hauy o mestre é um hipnotizador, a pessoa capaz de sugestionar e subordinar a vontade do outro. Para Pestalozzi e Froebel, o educador é um jardineiro infantil. Para Blonski o educador é um 
engenheiro da antropotécnica, ou da pedotécnica; é um técnico da antropocultura que existe paralelamente à pecuária e à fitocultura como ciência congênere. Muita gente tem comparado o trabalho do professor ao trabalho do artista e colocado em relevo as questões da criação individual. (VIGOTSKY, 2010: 446)

O autor defende que o verdadeiro segredo da educação é não educar:

O próprio aluno se educa. Uma aula que o professor dá em forma acabada pode ensinar muito mas apenas a habilidade e a vontade de aproveitar tudo o que vêm dos outros sem fazer nem verificar nada. Para a educação atual não é tão importante ensinar certo volume de conhecimento e utilizá-los. E isso se obtém apenas (como tudo na vida) no processo de trabalho. Sobre o professor recai um novo papel importante. Cabe-lhe tornar-se o organizador do meio social, que é o único fator educativo. (Vigotsky, 2010: 448)

Isso não significa que o professor não tenha um trabalho a realizar. Para que efetivamente ele seja o organizador do meio social, são necessárias habilidades, percepções do todo e das especificidades. Os planejamentos são essenciais, não como um modelo a ser seguido, mas como uma orientação de sua prática pautada na preparação dos conteúdos e metodologias adequadas. Daí a importância dos programas de formação continuada, propiciando trocas de experiências e aprimoramentos.

\section{CONSIDERAÇÕES FINAIS}

Considerando a assertiva "O que embrutece o povo não é a falta de instrução, mas a crença na inferioridade de sua inteligência" (RANCIĖRE, 2015: 64) devemos acreditar que todos somos capazes. Enquanto educadores, temos o dever de propiciar a nossos alunos formas múltiplas de aprendizagens, considerando seus trajetos, sua subjetividade. Não podemos permitir a subestimação em função de algumas dificuldades, sejam momentâneas, sejam permanentes.

O professor, comprometido com a qualidade do ensino, deve buscar a formação continuada, tendo claro seu papel, não de "mestre explicador", mas de facilitador, promotor de um ambiente propício a aprendizagem.

$\mathrm{Na}$ escola portanto o trabalho com o conhecimento não pode cingir-se à apreensão de conteúdos, como significativos em si mesmos, por mais que isso possa interessar também. Os conteúdos têm de ser 
experimentados na sua potência transformadora como disparadores da experiência de um processo de subjetivação. Dizendo de maneira figurada, os conteúdos não são pratos feitos a serem consumidos. Têm, pelo contrário, algo de "receita", convidando os alunos à feitura do próprio alimento. (LARA, 2016: 10).

Que nossas escolas sejam "cozinhas" de preparação do alimento saber! Comprometidos com o ensino dos conteúdos, que não podem ser desprezados, e valorizando o lúdico, vamos articulando fazeres que se somam como ingredientes de uma formação saudável e prazerosa. Assim como Gabriel, acreditamos que todas as crianças são capazes de aprender, da sua forma, no seu ritmo. Só precisam ser respeitadas e valorizadas em sua essência! Isso não significa que todo autista seja um gênio ou que todo disléxico seja um superdotado. Cada pessoa é um ser único, dotado de peculiaridades que devem ser consideradas no processo pedagógico.

Assim é possível efetivar a Inclusão. Respeitando as diferenças, valorizando as potencialidades, auxiliando a superação dos obstáculos, podemos construir a escola dos nossos sonhos!

\section{REFERÊNCIAS}

ALMEIDA, Laurinda Ramalho de; MAHONEY, Abigail Alvarenga. (Org.) Afetividade e aprendizagem: contribuições de Henri Wallon. São Paulo: Ed. Loyola, 2007. Disponível em: <https://books.google.com.br/books?id=RdnjVIcTodEC\&pg=PA54\&lpg=PA54\&dq=al bert+einstein+dificuldade+de+aprendizagem\&source=bl\&ots=1d12oS2gpG\&sig=ned hyZbsICuMqRS9AO298FVnje4\&hl=ptBR\&sa=X\&ved=0ahUKEwiMleKS8PrWAhUDN5AKHS44D0M4FBDoAQgpMAE\#v=0 nepage\&q=albert\%20einstein\%20dificuldade\%20de\%20aprendizagem\&f=false> Acesso em: 30 de jun. 2017.

BACHELARD, Gaston. A noção de obstáculo epistemológico; o primeiro obstáculo: a experiência primeira. In: A formação do espírito científico (1938). Tradução Estela dos Santos Abreu. Rio de Janeiro: Contraponto, 1996. p. 17-68.

BRASIL. Ministério da Educação. Nota técnica 04/2014. Disponível em: $<$ http://portal.mec.gov.br/secretaria-de-educacao-continuada-alfabetizacaodiversidade-e-inclusao/legislacao> Acesso em: 30 de jun. 2017.

BRASIL. LEI 12.796, de 4 de abril de 2013. Disponível em: <http://www.planalto.gov.br/CCIVIL_03/_Ato2011-2014/2013/Lei/L12796.htm> Acesso em: 30 jun. 2017. 
Brasil. Ministério da Educação e do Desporto. Secretaria de Educação Fundamental. Referencial curricular nacional para a educação infantil. Ministério da Educação e do Desporto, Secretaria de Educação Fundamental. Brasília: MEC/SEF, 1998.

DEMARTINI, Zeila de B. F; FARIA, Ana L. G. de; PRADO, Patrícia D.(org). Por uma cultura da infância: metodologias de pesquisa com crianças. 3 ed. Campinas, SP: Autores Associados, 2009.

FILHO, Antônio Pecci. et.al. Aquarela. In: Aquarela. Ariola, 1983. Lado 2, faixa 1 (4min 17s). Disponível em: <http://www.toquinho.com.br/album/aquarela-polygram1983/> Acesso em: 30 jun. 2017.

FREITAS, Ana Beatriz Machado de. Corpo e percepções no espectro autista. 2015. 150 f. Tese (doutorado) - Pontifícia Universidade Católica de Goiás.

Disponível em: <

http://webcache.googleusercontent.com/search?q=cache:LFinVfqBdJkJ:professor.pu cgoias.edu.br/SiteDocente/admin/arquivosUpload/1258/material/Tese \%2520Ana\%25 20Beatriz\%2520Machado\%2520de\%2520Freitas. \%2520CORPO\%2520E\%2520PE RCEP\%25C3\%2587\%25C3\%25830\%2520NO\%2520ESPECTRO\%2520AUTISTA.p

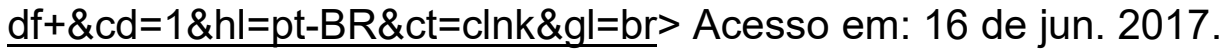

KRAMER, Sonia. A política do pré-escolar no Brasil: arte do disfarce. Rio de Janeiro: Achiamé, 1982.

LARA, Tiago A. Educação: conflitos, tarefa, desafio, perguntação, ética,

subjetivação, vida, cultura, aprendizagem, alegria. Juiz de Fora: Gryphon, 2016.

MANTOAN, Maria Teresa Eglér. Inclusão escolar - O que é? Por quê? Como fazer? São Paulo: Summus, 2015. 96p.

MEDRANO, Carlos Alberto. Do silêncio ao brincar: história do presente da saúde pública, da psicanálise e da infância. São Paulo: Vetor, 2004.

RANCIÈRE, Jacques. O mestre ignorante - cinco lições sobre a emancipação intelectual. Tradução Lílian do Valle. 3. ed. Belo Horizonte: Autêntica Editora, 2015. $192 \mathrm{p}$.

VECTORE, Celia. HORTA, Lígia Ribeiro. Estresse infantil: um estudo exploratório com pré-escolares. In: LOPES, José et. al. Investigações e saberes: psicologia em movimento. Uberlândia: EDUFU, 2012. Páginas 129 - 134.

VIGOTSKY, Lev Semenovich. 1896-1934. Psicologia pedagógica / L. S. Vigotsky. Tradução do russo e introdução de Paulo Bezerra. $3^{a}$ ed. São Paulo: Editora WMF Martins Fontes, 2010. 